\title{
RE-EXAMINING THE RATIONALE FOR STRATEGIC ASSESSMENT: AN EVALUATION OF PURPOSE IN TWO SYSTEMS
}

\author{
SAMUEL HAYES* $*$, ADAM BARKER $\dagger$ and CARYS E. JONES $\dagger$ \\ - University of Liverpool, Department of Geography and Planning, School of Environmental \\ Sciences, University of Liverpool, 74 Bedford Street South, Liverpool, L69 7ZT, UK \\ samuel.hayes@liverpool.ac.uk *corresponding author
}

$\uparrow$ University of Manchester, Department of Planning \& Environmental Management, School of Environment, Education and Development, Humanities Bridgeford Street Building, University of Manchester, Oxford Road, Manchester, M13 9PL, UK

adam.barker@manchester.ac.uk and carys.jones@manchester.ac.uk

Key Words: Strategic Environmental Assessment; Sustainability Appraisal; Sustainability Assessment; impact assessment; sustainability; sustainable development

\begin{abstract}
Strategic forms of impact assessment have seen increased application around the world since their conception. Expansion has produced considerable variation and this range of tools and processes can create practitioner confusion and blurred boundaries in practice. This research draws on empirical data from England and Scotland to examine different systems to understand how the purposes of strategic assessment are framed and to consider how purposes are translated into practice. Four key purposes of strategic assessment are examined; overcoming EIA shortcomings, strategic thinking, representation of the environment and consideration of sustainability. It is concluded that various scales (international, national, local and individual) influence how strategic assessment purpose is framed. We find that as multiple purposes come together they interact, with regulatory compliance potentially dominating. Strategic assessment is also found to be described as information provider, and excluded or distant from strategic thinking as part of plan formulation.
\end{abstract}

\section{Introduction}

While the term Strategic Environmental Assessment (SEA) was first used by Wood and Djeddour (1989) in the 1980s in their report to the European Commission, the advent of strategic assessment more generally can be traced back to 1969 and the National Environmental Policy Act (NEPA) in the United States (Cashmore et al., 2008; Fischer, 2007; Jones et al., 2005). Since this early legislation and use, strategic assessment systems have been introduced in over 60 countries around the globe (Fundingsland Tetlow and Hanusch, 2012). As strategic assessment has been introduced in many contexts around the world it has taken on different forms, leading Partidário (2000, p.655) to describe strategic assessment as a 'family of tools' rather than adopting a prescriptive definition.

Describing this family of tools, Partidário (2000) emphasised the need for strategic assessment practice to be tailored to the policy, plan or programme making context. Similarly, Brown and Therivel (2000) 
emphasised the need for the consideration of, not only the definition or methods of strategic assessment, but also substantive elements of practice (for example, principles and effectiveness) and the organisational setting where strategic assessment is practiced. Similarly, Vincente and Partidário (2006, p.697) noted that while descriptions of SEA were established, consideration of 'what SEA really is' remained beyond consensus. Moreover, as Bina (2007) highlighted, the development of strategic assessment has seen an increasing list of expectations assigned to it, leading to the need to take stock of and pay attention to purpose, to explore the needs strategic assessment responds to, and the problems it seeks to solve.

More recent literature updates this and provides an extensive list of possible purposes and benefits of strategic assessment (Fundingsland Tetlow and Hanusch, 2012) and after more than four decades of practice and development many systems incorporate these purposes in various permutations (Noble and Nwanekezie, 2016). Noting increased consensus on how strategic assessment differs from Environmental Impact Assessment (EIA), Noble and Nwanekezie (2016) argued that this consensus leaves crucial questions about the fundamentals of strategic assessment unanswered. In addition, associated with this range of tools and wealth of possible purposes, practitioner frustration, confusion, ill-defined roles and blurred boundaries between tools have been reported (Sheate, 2011; Tajima and Fischer, 2013); further confusing strategic assessment purpose and practice. Moreover, arguing that strategic assessment should be understood as a multi-faceted and multi-purpose tool, Noble and Nwanekezie (2016) also highlighted inflexible institutional arrangements and limited strategic thinking as problematic and called for strategic assessment to be reconceptualised as a fundamentally strategic process. Thus, literature raises questions about how well understood this family of tools is in practice: are purposes described in literature visible and are they successfully incorporated in practice?

Rather than reproduce a list of purposes, this article considers system variation to investigate how strategic assessment systems frame purposes and how these purposes are incorporated in practice. The aim of this article is, therefore, to re-examine the purposes of strategic assessment systems and the relationship between multiple purposes in practice, specifically asking questions about their compatibility. To do this we first consider how purpose is discussed in literature to clarify and reflect on how the various purposes frame strategic assessment. The research methods and analytical approach are then introduced. Analysis is then presented which draws on empirical data from four case studies from England and Scotland, where distinct systems of strategic assessment, Sustainability Appraisal ${ }^{1}$ (SA) and SEA, are carried out. Finally, a concluding discussion draws out the implications for wider strategic assessment practice, international relevance is discussed, and conclusions offered.

\section{Framing Strategic Assessment Purpose}

This section provides an overview of how the purpose of strategic assessment is framed in order to present a clear grounding for analysis. Literature provides us with some central tenets of strategic assessment, laying down the fundamental aspects of its purpose and justification. These are categorised as; overcoming shortcomings of EIA, strategic thinking, representation of the environment and consideration of sustainability.

\footnotetext{
${ }^{1}$ Sustainability Appraisal is a common term in the UK, but the term Sustainability Assessment is more commonly used internationally. Although some variation does exist between the two they are considered to share core characteristics.
} 
The first rationale for strategic assessment discussed here describes strategic assessment developing in response to shortcomings or limitations of project level EIA. So called shortcomings improved by the introduction of strategic assessment include the perceived need for consideration of the environment at earlier decision stages (Partidário, 2000; Morrison-Saunders and Fischer, 2006), the need for more effective reasoning and decision-making at plan and programme levels, support for general 'good governance' principles (Fischer, 2007), as well as improved consideration of alternatives and the treatment of cumulative, indirect, synergistic, long-range, delayed and global impacts (Wood, 2003).

The early development of strategic assessment, particularly SEA practice in the EU, arguably has its roots in project level assessment (Bina, 2007), EIA having been formally established in the EU over a decade before SEA. This rooting of strategic assessment in EIA is visible in many of the early descriptions. Lee and Walsh (1992) described strategic assessment as, at its most simple, providing the opportunity to consider the impacts of non-project actions; framing strategic assessment as EIA at a strategic tier or scale.

The development of strategic assessment in response to shortcomings of EIA and the application of EIA-type assessment at earlier and higher tiers of decision-making potentially also frames how strategic assessment is practiced - possibly instilling a procedural and technical-rational perspective. A technical-rationalist perspective views assessment as an idealised and stepwise processes involving objective identification, analysis of alternatives, presentation of objective information and decisionmaking (Elling, 2009; Fischer, 2003; Kørnøv and Thissen, 2000; Richardson, 1996). Gasparatos et al. (2009) also argued that many forms of strategic assessment are based on a reductionist paradigm, aiming to aggregate and reduce complex and diverse information for input into decision-making processes. The primary assumption justifying this perspective is that scientifically valid information produces better decisions through a process of rational choice between alternatives (Kørnøv and Thissen, 2000).

However, as Weston (2004) argued, the fundamental problem with the assumption of a technicalrational perspective in assessment is its normative basis and several authors have argued that descriptions of impact assessment as a technical-rational process does not reflect the complexity of realworld decision-making (Cashmore et al., 2004; Fischer, 2003; Kørnøv and Thissen, 2000; Nitz and Brown, 2001). Kørnøv and Thissen (2000) argued that a technical-rational conception of assessment is only likely to be successful when considerable social consensus exists along with ample knowledge. Lower social consensus, greater conflict of opinion, a lack of knowledge, high uncertainty, multiple objectives with unclear preferences, the influence of human behaviour, value judgements and specific norms all serve to reduce the appropriateness of a technical-rational view of decision-making (Kørnøv and Thissen, 2000; Verma, 1996).

Moreover, Cashmore et al. (2008) noted that studies considering attempts to increase 'rationality' in assessment have shown that a pursuit of scientific rationality may actually serve to conceal the political nature of decision-making. Indeed, strategic assessment of policy options has been described as a process of rationalisation rather than the application of rationality (Owens, 2005). Providing an alternative conceptualisation of how strategic assessment might participate in decision-making, several authors have described it as a 'knowledge broker' or means of communication; bringing together multiple perspectives and rationalities, and mediating between them (Sheate and Partidário, 2010; Morgan et al., 2012; Partidário and Sheate, 2013). It is therefore important to recognise that strategic assessment cannot be described as a purely technical-rational or scientific tool and that it potentially plays a role to facilitate communication and mediate during decision-making. This may, in turn, 
influence practice, for example, influencing what roles are set for strategic assessment and what methods are considered appropriate.

However, framing of strategic assessment as purely based on EIA and including a technical-rational perspective does something of a disservice to early conceptions of EIA. As Bina (2007) noted, early conceptions of EIA included its application to various tiers of decision-making (for example, NEPA in 1969). The development, therefore, of SEA arguably puts into practice principles which have been part of assessment since its inception (Bina, 2007; Noble and Nwanekezie, 2016). Indeed, this is the basis of a second line of argument used to frame the role of SEA; the notion of 'strategy'. Bina (2007) emphasised the importance of being strategic, arguing that strategic assessment is not so named because it is concerned with strategic tiers of decision-making, e.g. policies, plans and programmes, but because the assessment is, itself, strategic.

Emphasising the importance of strategy, Noble (2000) described this as the key component; framing strategic assessment as related to the general, the very beginning of a process, and to the establishment of objectives and courses of action. This focus on the strategic also changes understanding of how strategic assessment might tackle shortcomings identified in EIA. For example, forecasting and the prediction of impacts, fundamental to EIA, is also part of strategic assessment but can be supplemented by backcasting (Noble, 2000). Utilising both forecasting and backcasting enables strategic assessment to consider not only the implications of certain actions (forecasting), but also which actions or alternatives would be necessary to bring about desired objectives (backcasting). The exploration of purpose in this article will consider how strategic thinking is included within UK case studies. Specifically, we will examine the compatibility of framing strategic assessment as responding to shortcomings of EIA, and perhaps adopting a technical-rational perspective, with strategic thinking.

In addition to responding to shortcomings of EIA practice and strategic thinking, it is also argued that two further tenets of strategic assessment can be distinguished which frame strategic assessment in subtly different ways. The first is to act as an advocate for the environment (Morrison-Saunders and Fischer, 2006). Van Doren et al. (2013), drawing on the EU SEA Directive ${ }^{2}$, emphasised the role of SEA to provide environmental protection, and Therivel and Partidário (1996) argued for SEA to provide stronger environmental representation and to mainstream environmental concerns. This expression of purpose frames strategic assessment as environment focused and emphasises its role to be an advocate and influencer in favour of the environment - particularly, it is noted, SEA practice informed by, and developing in response to, EU legislation.

Related to representation of the environment, contribution to sustainable development or sustainability is also widely cited as a key purpose of strategic assessment (Cashmore et al., 2007, Fischer, 2007, Glasson et al., 2005, Lee and Walsh, 1992, Therivel, 2004). This aim is common to literature discussing both SEA and SA and is held by the strategic assessment systems in England and Scotland. However, these two aspects, representation of the environment and a focus on sustainable development, begin to articulate a distinction between the systems of England and Scotland which are the subject of this article, with representation of the environment associated more with SEA in Scotland and a broad consideration of sustainable development through SA in England.

\footnotetext{
${ }^{2}$ Directive 2001/42/EC on the assessment of the effects of certain plans and programmes on the environment (SEA Directive)
} 
Support for a distinction along such lines also comes from those who have attempted to define SA more generally. Hacking and Guthrie's (2008) explanation of SA simply describes a process aiming to direct decisions towards sustainability - again positioned as an influencing force on plan formulation. Devuyst (2001) similarly defined SA as a tool to aid policy and decision makers when producing and considering actions to make society more sustainable. Fundamental to the emergence of forms of SA was the prominence of the concept sustainability and a desire to assess performance and quantify progress (Gasparatos et al., 2009). This focus on the concepts of sustainability has profound effects on SA breadth, and Gibson (2006) argued, because the concepts are essentially about integration, SA should reflect this. Similarly, Smith and Sheate (2001) argued that SA can be seen as a shift towards integrated assessment and decision-making as consideration is given to social, economic and environmental implications. More recent discussion of SEA suggests that the notion of integrated assessment may have become more widespread in general understandings of SEA (Gibson et al., 2010; White and Noble, 2013); however, whether and how quickly this translates to practice remains unclear and worthy of investigation.

It is argued here that the distinction discussed above can be seen in UK practice and can act as a simple and useful, although admittedly imperfect, distinguishing feature of SEA and SA when considering UK practice. That is, that SA in England is more directly associated with progress towards sustainability or sustainable development through a broad consideration of social, economic and environmental aspects. SEA in Scotland meanwhile, although arguably still directed at this overarching aim, is more environment focused and concerned with mainstreaming and representing the environment in policy, plan and programme formulation (Illsley et al., 2014). It is the possibility of this distinction arguably exemplified by SA in England and SEA in Scotland which provides a point of entry to analyse system variation and is explored in this research.

Based on the review of literature, we have identified four key tenets or purposes of strategic assessment which frame strategic assessment practice. These are; EIA shortcomings, strategic thinking, representation of the environment and consideration of sustainability. These tenets are not argued to be mutually exclusive but broad purposes which interact with one another and influence how strategic assessment is practiced - it is this interaction which this paper examines. Literature has also problematised these tenets, highlighting the potential for inappropriate technical-rational assumptions and raising questions about the compatibility of such assumptions with strategic thinking or when strategic assessment is acting as a knowledge broker, advocate or influencer. This article, therefore, builds on the existing literature to consider how different systems frame strategic assessment purpose and to examine the compatibility of these purposes, how these purposes interact and how they are incorporated into practice.

\section{Methods}

The use of the case study in research arises from a desire to understand complex phenomena where a holistic view of real world events is sought, such as organisational, managerial, decision or implementation processes (Yin, 2009). A case study methodology was employed in this research to gain an understanding of the purposes of strategic assessment as applied in real world examples drawn from England and Scotland. Examining two systems of strategic assessment enables analysis and comparison of the contexts within which strategic assessment purpose is framed and practiced. 
When conducting multiple case study research, it is necessary to develop a robust approach to case selection and to consider the logic of replication. This enables the researcher to increase the robustness of findings (Yin, 2009); however, replication should not be understood to mean that universal generalisation is possible as if from a larger 'sample' of cases (Robson, 2011). Small ' $n$ ' replication in this instance is justified to increase the external validity of findings and the approximate generalisability of a proposition (Levi-Faur, 2006), enabling theoretical generalisation rather than statistical or universal generalisation.

Yin's (2009) process of 'theoretical replication' was used to select cases for which there is a theoretical explanation for their comparison. In this instance in order to explore system variation and interaction of multiple purposes in practice it was necessary to select cases from assessment systems which can be said to have divergent purpose. England and Scotland were selected to explore how system variation with regard to rationale may condition and influence strategic assessment practice as well as show how multiple purposes are interacting in different systems. To enable a view of specific practice, four embedded cases were selected; two from England and two from Scotland (see Figure 1). The embedded cases were selected to give access to strategic assessment practice at different strategic scales (local and regional development plans) in each country (Table 1).

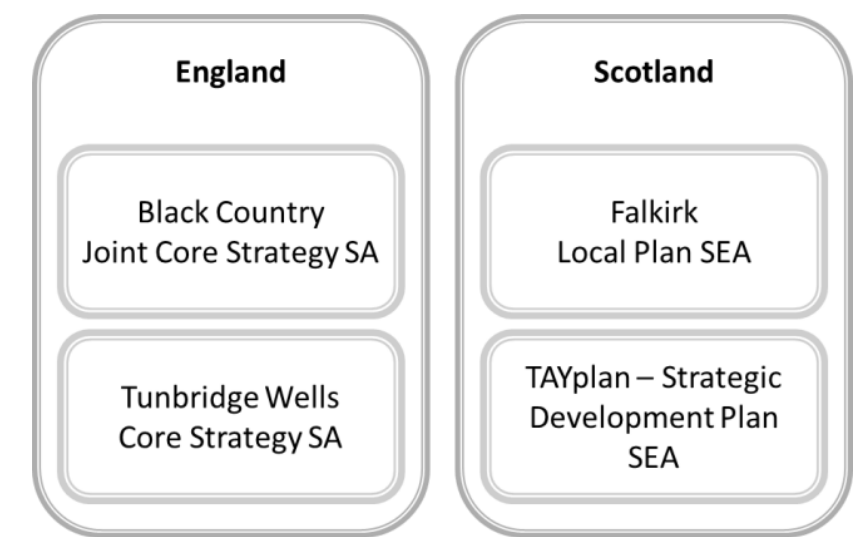

Figure 1: Selected embedded case studies from England and Scotland.

\begin{tabular}{|c|c|}
\hline \multicolumn{2}{|c|}{ Table 1: Case study context information } \\
\hline $\begin{array}{l}\text { Black Country Joint Core Strategy SA } \\
\text { - Sub-regional scale } \\
\text { - Collaboration of Local Authorities: } \\
\text { - Dudley Metropolitan Borough Council } \\
\text { - Sandwell Metropolitan Borough Council } \\
\text { - Walsall Council } \\
\text { - Wolverhampton City Council } \\
\text { - SA prepared by consultancy }\end{array}$ & $\begin{array}{l}\text { TAYplan Strategic Development Plan SEA } \\
\text { - Regional scale } \\
\text { - Collaboration of Local Authorities: } \\
\text { - Dundee City Council } \\
\text { - Angus Council } \\
\text { - Perth and Kinross Council } \\
\text { - Fife Council } \\
\text { - SEA prepared in-house }\end{array}$ \\
\hline $\begin{array}{l}\text { Tunbridge Wells Core Strategy SA } \\
\text { - } \quad \text { Local scale } \\
\text { - } \quad \text { Single Local Authority } \\
\text { - } \quad \text { SA prepared by consultancy }\end{array}$ & \begin{tabular}{l}
\multicolumn{2}{l}{ Falkirk Local Plan SEA } \\
- $\quad$ Local scale \\
- $\quad$ Single Local Authority \\
- $\quad$ SEA prepared in-house \\
\end{tabular} \\
\hline
\end{tabular}

Documents analysed included assessment reports produced at the various stages of SA and SEA and related documents such as plan iterations and consultation reports. The majority of interviewees were drawn from those associated with each embedded case and included in-house assessment practitioners, planners liaising with consultants, assessment consultants and statutory consultees. A small number of additional interviews were also conducted with experts with national oversight in each country. In total, 
32 interviews were conducted. Interviewees have been anonymised and given a reference number (e.g. 'Interviewee 1'). Interviewees are also referred to with an indication of which system or embedded case they are associated with.

The analytical approach utilised thematic coding, involving the coding of data and the grouping of codes into themes (Robson, 2011). Saldaña (2009) highlighted the need for gradual refinement in the process of developing codes, categories, themes or concepts, and their interpretation. Analysis in this research followed the phases of thematic coding described by Robson (2011, p.476) which are; familiarisation with data, generating initial codes, identifying themes, constructing thematic networks, and interrogation and interpretation.

\section{Examining Strategic Assessment Purposes and How They Condition Practice}

The discussion and analysis of empirical data is split into two parts, beginning with examination of the SA and SEA systems in England and Scotland and the individual cases to explore whether and how the purposes identified from literature are represented in each system. This analysis thus develops understanding of whether, and in what configuration, these broad purposes are reflected in the systems of England and Scotland. The second section of analysis turns to the relationship and interaction between the purposes in SA and SEA practice to examine issues such as compatibility and dominance.

\section{Examining strategic assessment systems}

At the time of the case studies, the primary legislation driving strategic assessment was the EU SEA Directive. Introduced in 2001, the SEA Directive formalised requirements for the application of strategic assessment for all EU Member States. Variation arises within the UK as implementation of the SEA Directive is devolved to the four administrations of the $\mathrm{UK}^{3}$ (Jackson and Illsley, 2007).

The SEA Directive therefore forms an important part of the context within which strategic assessment in the UK operates and it is important to briefly revisit how the EU legislation frames strategic assessment purpose. Article 1 expresses the Directive's overall objectives:

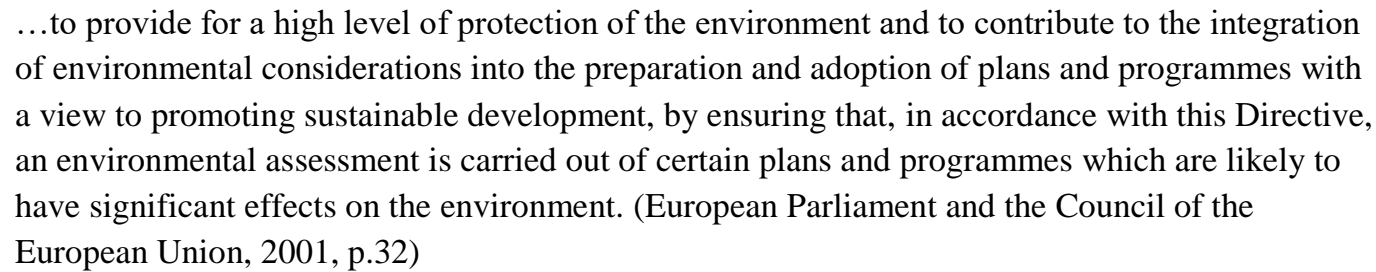

The purposes included within Article 1 make clear the intention of the SEA Directive to contribute to environmental protection, but also to contribute to sustainable development through the integration of the environment into plans and programmes. The scope of the SEA Directive is laid out in Article 3 which provides a list of likely sectors to be included and, as in Article 1, it makes the connection

\footnotetext{
${ }^{3}$ At the time of this research the UK was divided into four administrations; the UK Government, the Northern Ireland Assembly, the Scottish Government and the Welsh Assembly. The UK government provides legislation for England.
} 
between the SEA Directive and significant environmental effects (European Parliament and the Council of the European Union, 2001).

The guidance produced by the European Commission Environment Directorate-General, Implementation of Directive 2001/42/EC on the Assessment of the Effects of Certain Plans and Programmes on the Environment (European Commission Environment Directorate-General, 2001), provides further insight into the broad purpose envisaged for strategic assessment following the SEA Directive.

\begin{abstract}
The Strategic Environmental Assessment (SEA) Directive is an important step forward in European environmental law. At the moment, major projects likely to have an impact on the environment must be assessed under Directive 85/337/EEC [EIA Directive]. However, this assessment takes place at a stage when options for significant change are often limited. Decisions on the site of a project, or on the choice of alternatives, may already have been taken in the context of plans for a whole sector or geographical area. The SEA Directive - 2001/42/EC - plugs this gap by requiring the environmental effects of a broad range of plans and programmes to be assessed, so that they can be taken into account while plans are actually being developed, and in due course adopted. (European Commission Environment Directorate-General, 2001, p.1)
\end{abstract}

The SEA Directive is again presented as environment focused and the importance of filling a perceived 'gap' above project level EIA is emphasised. Strategic assessment is cast as EIA at a strategic level, although potential for strategic thinking is suggested as consideration of options and alternatives is noted.

In England, the Planning and Compulsory Purchase Act 2004 and the Environmental Assessment of Plans and Programmes Regulations 2004 provide the primary stimulus for practice requiring 'an appraisal of the sustainability' (UK Government, 2004, p12) and transposing the SEA Directive respectively (Office of the Deputy Prime Minister, 2004). As well as initiating the need for SA the Planning and Compulsory Purchase Act 2004 also makes the link between conducting SA and achieving sustainable development (UK Government, 2004, p.22). While several key pieces of planning guidance also emphasise the need for SA to consider social, environmental and economic impacts (Department for Communities and Local Government, 2008; Office of the Deputy Prime Minister, 2005). The 2014 National Planning Practice Guidance updates previous guidance but maintains the consideration of environmental, economic and social impacts of plan proposals in SA in England (Department for Communities and Local Government, 2014).

In Scotland, the Environmental Assessment (Scotland) Act 2005 transposes the SEA Directive and differentiates Scottish legislation from English by requiring 'an environmental assessment in relation to the plan or programme' (Scottish Government, 2005, p.1). The Planning etc. (Scotland) Act 2006 also formally makes the connection between strategic plan-making and sustainable development (Scottish Government, 2006, p.4). Guidance on SEA in Scotland has also been updated; moving from the SEA Toolkit to the Strategic Environmental Assessment Guidance, nevertheless, the focus of SEA on the environment is maintained (Scottish Government, 2013). The link between integration of the environment through SEA and the achievement of sustainable development is also emphasised in the guidance (Scottish Government, 2013).

The above focuses on formally stated purposes present in legislation and guidance, however, consideration of the political context of SA and SEA in England and Scotland enables analysis of the political context for strategic assessment in the two countries and how strategic assessment purpose is 
represented beyond formal documents.

Within Scotland, evidence suggests there has been broad support for strategic assessment and, more specifically, for environment focused SEA within recent governments. The partnership agreement of the Scottish Labour Party and the Scottish Liberal Democrats produced in May 2003 highlighted their ambition and intention to introduce SEA to '...ensure that the full environmental impacts of all new strategies, programmes and plans developed by the public sector are properly considered' (Scottish Labour Party and Scottish Liberal Democrats, 2003, p.48).

In addition, during development of the Environmental Assessment (Scotland) Act 2005 the then Scottish Executive consulted on the appropriateness of the inclusion of social and economic factors in strategic assessment. The Scottish Executive Environment Group went on to explain that, '...the Scottish Executive intends for the Bill to have a clear environmental focus' (Scottish Executive Environment Group, 2003, p.32). Moreover, the Scottish Government described the motivation to introduce the Environmental Assessment (Scotland) Act 2005 as, in part, related to establishing Scotland as a 'world leader' in SEA (Scottish Government, 2011).

It is argued that within Scotland there was support for SEA and for using strategic assessment as a means to consider the environment - although how much this remains part of the Scottish National Party led government is less clear. Nevertheless, interview evidence reinforces the validity of this conclusion with respect to the time of the embedded cases as one interviewee within the Scottish Government explained:

\footnotetext{
'My understanding is that as the driver was environmental, the aim should be to achieve what you can by focusing on the environmental component; I mean it [the SEA Directive] is an environmentally driven Directive.' (Scottish Government, Interviewee 28)
}

By contrast, reviewing the transposition of the SEA Directive within England reveals a less supportive environment. Commenting on the criticism that the broader focus of SA represents a watering down of the SEA Directive, one interviewee emphasised that watering down was not something for which there was political desire, or which formed part of the strategy for implementing the SEA Directive in England (Department for Communities and Local Government, Interviewee 24). Nevertheless, it is found that wider political support for strategic assessment within England, of the sort described in Scotland, was not present. It is argued that there has been a less proactive and engaged approach from the UK Government with regard to implementing and developing strategic assessment within England, as the same interviewee described:

\footnotetext{
'They [Scotland] have been proactive; the civil servants have been instructed to be proactive, to go out, to advocate SEA, to make sure it's working and to do research on it. We [England] haven't had that kind of political engagement. It wasn't something that the Labour administration was that keen on. They weren't against it, they were quite happy to implement the SEA Directive, but [civil servants] were left largely to work out how to do it. We were not encouraged to bring forward a lot of ideas...' (Department for Communities and Local Government, Interviewee 24)
}

While compliance with the SEA Directive is not questioned, there is the sense that there was less political support for, or interest in, strategic assessment in England than in Scotland. It is argued that the political support visible in Scotland, and largely absent from the English experience, conditions how strategic assessment is framed in each context by providing endorsement for strategic assessment in line with the formally stated purposes. Moreover, this difference in context potentially influences how 
strategic assessment is practiced with greater encouragement to engage with SEA in Scotland and less endorsement for innovative SA practice in England.

Consideration of how this formal and national context conditions practice can be found by examining the embedded cases. In England, the SA documents for the Black Country and Tunbridge Wells, included statements describing SA as a tool to assess or consider the social, environmental and economic factors of their plans (Tunbridge Wells - Waterman Environmental, 2005, p.62; Black Country - Tesserae Environmental Consultants, 2007, p.2). The Falkirk and TAYplan SEA documentation demonstrates the environmental focus of the Scottish SEA system, with both including statements highlighting the role of SEA to integrate or consider environmental factors (TAYplan Strategic Development Planning Authority, 2009, p.2, Falkirk Council, 2007, p.3). It is apparent that, on the surface at least, the cases reflect the formally stated purposes of their respective systems.

Overall, we see evidence of multiple purposes reflecting the tenets for strategic assessment identified from the literature and have clarified how these are presented at an EU and national level in England and Scotland. At the EU level, we do see an environmental focus, qualified as mainstreaming the environment in order to contribute to sustainable development. Moreover, strategic assessment purpose is also framed as tackling project level shortcomings and plugging gaps. Importantly, we also see evidence that the relationship between some of these tenets is framed in distinct ways in England and Scotland. Both SA and SEA are expected to contribute to sustainable development, but SA in England is described as contributing by considering environmental, economic and social aspects while SEA's contribution in Scotland is associated with integrating the environment into decision-making. In addition to a clear representation of the known national differences, we also see variation in political commitment or endorsement of strategic assessment and note that this may also impact on practice.

\section{Examining multiple purposes}

Both literature and our analysis of the two strategic assessment systems indicate that multiple purposes are held for conducting strategic assessment. Attention now focuses on understanding how these multiple purposes are manifested in practice and the relationship between them. We consider whether certain purposes dominate and further explore compatibility by considering how and whether strategic thinking is meaningfully included in practice alongside other purposes.

\section{Examining compatibility; regulatory compliance as a dominant purpose?}

It is important to understand the ways that these multiple purposes are being translated into strategic assessment practice, and to examine their interpretation, their relative weights or importance, and their potential for dominance. From our analysis of the case studies it is found that regulatory compliance is often placed in a dominant position - potentially undermining, or impacting on, other purposes.

Each of the embedded cases understandably acknowledged the regulatory requirement for strategic assessment, with clear reference made to both the SEA Directive and the legislation through which England and Scotland have transposed it. For both the English cases, that the SA formally fulfils the requirements of the SEA Directive was expressly described. However, in addition to acknowledgement of the regulatory requirements, there is also considerable reference within the documentation to specific elements of assessment that are legislated for, or included within regulations. 
Within the Black Country documentation reference is made to several articles of the SEA Directive and to the Town and Country Planning (Local Development) (England) Regulations 2004, including the need to include certain assessment criteria, to undertake consultation, to submit the SA report to the Secretary of State, to monitor significant environmental effects, and to make certain information publically available post-adoption. In the Falkirk case, reference is also made to specific requirements of the SEA Directive along with the Environmental Assessment (Scotland) Act 2005, highlighting the specific need to produce the environmental report itself, produce a post-adoption statement explaining how the environmental report has been taken into account, and to provide a description of proposed monitoring. In the TAYplan case, reference is made again to the need, under the SEA Directive and the Environmental Assessment (Scotland) Act 2005, to produce an environmental report, to consider reasonable alternatives, and to consider certain topics within their assessment.

The prominence given to the discharging of responsibilities regarding procedural stages and specific requirements of legislation and regulation indicates a strong desire to demonstrate regulatory compliance - again, understandably an important part of strategic assessment reports. However, what effect the framing of strategic assessment purpose so closely with regulatory requirements has on practice and the extent to which compliance may dominate the multiple purposes given for SA or SEA requires further analysis.

This Falkirk interviewee described concern that fear of failure to comply, discourages tailored or novel SEA practice; often, as they note, exactly the sort of innovative practice called for in guidance and practice reviews:

'I think one of the problems I have with SEA is there is an underlying fear it is a part of the regulatory process and if we don't do it right there is the possibility for legal challenge. I think there is a tension in the way we are being driven by Government, in that, when you hear the SEA talk at all these conferences and stuff, [for example] "we want shorter SEAs, we want you just to be strategic and just focus on the impacts' etc. and only significant impacts, take more of an overview of things". When you actually pose specific questions, there is always this precautionary approach, "be careful that you don't put in something unless you assess it" sort of thing.' (Falkirk, Interviewee 9)

This interviewee identified a tension between desires to demonstrate compliance and calls for novel or bespoke practice. Other interviewees involved in various capacities in the Black Country and Tunbridge Wells cases also provided evidence to suggest regulatory compliance may have played a role in shaping their own practice. The extract below is an example of the weight given to regulatory compliance and evidence of the potential for regulatory compliance to dominate.

'I think the purpose of the SA was literally to tick the box, to demonstrate that the strategies proposed were sound.' (Black Country, Interviewee 5)

This extract represents one of the strongest views on regulatory compliance. While variation exists between the different interviewees in each case, for the most part we see acknowledgement of the legislative requirements and its casting as one of several purposes. This is expressed succinctly by the following TAYplan interviewee, who, when asked about the purpose of SEA, responded; 'Beyond the fact that you had to do one?' (TAYplan, Interviewee 18). Other interviewees also expressed the desire that assessment should be justified on its own merits in addition to regulatory compliance, as exemplified by the following extract: 
'...we were very keen that it wasn't a case of doing an SEA/SA for its own sake, for the sake of doing it to meet the regulations...' (Black Country, Interviewee 4)

Indeed, Scottish SEA guidance expressed similar aspirations to maintain both regulatory compliance and other purposes, and that the contribution of SEA to addressing environmental problems is still an important purpose in their view:

Fundamentally SEA is a statutory obligation for qualifying plans. However, notwithstanding this fact, a SEA can provide a valuable opportunity to identify and address the environmental implications of public plans. (Scottish Government, 2013, p.4)

Our analysis shows that there exists a strong awareness of the formal legislative requirements for SA and SEA. It is also found that in some cases there is evidence to suggest that compliance with legislation can dominate and represent the main purpose for strategic assessment. Moreover, we find that there exists a potential tension between regulatory compliance and conducting bespoke assessment or undertaking novel practice. However, the cases also highlight the potential for multiple purposes to be held in conjunction with compliance. Indeed, some respondents emphasised a concerted effort to ensure that compliance did not become the primary purpose. We argue, therefore, that desires to demonstrate regulatory compliance may come to dominate strategic assessment purpose, potentially discouraging tailored or bespoke practice and that resisting this relies on individuals working in practice taking concerted and conscious actions.

\section{Examining compatibility; Meaningful inclusion of strategic thinking?}

Having identified potential dominance of regulatory compliance and concerns about a possible tension between this and other purposes or discouragement of bespoke practice, attention now turns to how strategic thinking more specifically fits into this mix of purposes. As one of the key tenets of strategic assessment, and importantly differentiating it from EIA, further consideration of how strategic thinking as a purpose is manifested in the case studies is vital. It is found that there is ambiguity regarding how, or indeed if, strategic thinking is incorporated into strategic assessment and how strategic thinking feeds into the plans being assessed.

Analysis of documentation from the cases provides ambiguous evidence of how strategic thinking forms part of strategic assessment. The TAYplan case provides evidence that strategic thinking may form part of how SEA was conceived.

The SEA process is intended to ensure that the possible environmental effects both positive and negative of plans, programmes and strategies are fully considered and taken account of in the course of their development. (TAYplan - Perth \& Kinross Council, 2009, p.11)

This formal statement of SEA purpose from the TAYplan scoping report certainly places SEA at a strategic tier, and suggests possible inclusion of strategic thinking, in so far as SEA is described as contributing to plan, programme or strategy development. The Falkirk case similarly describes SEA as operating at a strategic tier, and identified SEA as commenting on strategic actions to ensure the environment is considered, again suggesting SEA was expected to participate in strategic thinking to some degree. 
SEA is a process by which the potential environmental effects of strategic actions, that is policy level actions rather than specific development proposals, are considered. (Falkirk - Falkirk Council, 2011, p.11)

However, these descriptions lack clarity about how far SEA is actually included in strategic thinking and decision-making. It is argued that this alludes to a distinction between it either participating fully in strategic thinking, or contributing information on impacts during plan formulation.

The Black Country case provides further evidence that strategic thinking may be absent from some elements of SA practice; or rather that SA is excluded from some periods or aspects of strategic thinking. In this instance, it was noted that SA was excluded from generation of alternatives and was framed as a tool to document rather than contribute to strategic thinking around alternatives:

It is not the purpose of the SA/SEA process to identify options and Joint Core Strategy authors have already done a great deal of work in this respect. The SA report does however need to include a comprehensible section documenting how alternatives were identified and which of those should be rejected or indeed further enhanced. (Black Country - Tesserae Environmental Consultants, 2008, p.130)

Evidence from the Tunbridge Wells case also raises questions about whether strategic thinking was part of SA, specifically that SA was not included within the process of developing or influencing options:

SA promotes sustainable development by identifying the likely sustainability effects of the proposed objectives and broad policy options for the Core Strategy, together with making recommendations for reducing, mitigating or compensating any significant adverse effects and maximising positive effects. (Tunbridge Wells - Waterman Environmental, 2007, p.1)

There is evidence from the four cases that SEA and SA had a relationship with strategic thinking, and was intended to influence strategic thinking; however, there is also the suggestion that strategic assessment contributed to, rather than participated in, strategic thinking undertaken elsewhere as part of plan formulation.

Analysis of interview data provides further evidence of how strategic thinking featured in each of the cases. TAYplan Interviewee 10 suggested that strategic thinking to some degree featured in their work, describing their desire to influence and contribute to the environmental sustainability of the area, that contributing to this strategic goal was part of their motivation for SEA:

'We [the SEA team] were trying to influence the plan, and, certainly from our perspective, it was about contributing to the environmental sustainability of the area and hopefully the wider sustainability of the area. I think that was one of our strong motivations.' (TAYplan, Interviewee 10)

Similarly, a Falkirk interviewee involved in, but not leading, the SEA process, also reported a desire to be part of decision-making for the best environmental option. Although they specifically described the 'strategic level', perhaps more a description of the tier, they do still allude to participating in strategic thinking: 
'It's to ensure that the plan is environmentally friendly if you like, at a strategic level. That the best environmental options pop out at the end. So, hopefully we're looking at alternatives, that the best option is chosen.' (Falkirk, Interviewee 8 )

Another Falkirk interviewee provided greater detail, noting that their experience spanned a period of considerable flux and development in legislation and SEA in Scotland, which had perhaps affected how they approached SEA and how strategic the assessment was.

'I think a lot of it [our motivation for SEA] was about documenting, it wasn't about influencing decision-making it was about documenting impacts, and I think early on that was very much the whole idea of the SEA. I think the fundamental influence on decision-making that's become more important. In the early days I think it was more about quantifying impacts.' (Falkirk, Interviewee 9)

Interviewees from the Tunbridge Wells case more specifically noted that the ability to participate in, or influence, strategic thinking and decision-making was limited or blocked.

'I think in some ways it [SA] was kind of used for what was going to be done anyway rather than influencing what was going to be done.' (Tunbridge Wells, Interviewee 13)

'But I don't think it was really with the aim of influencing how you deliver policy; how you draw up your policies [and] feeding into your policy development was kind of blocked in some ways.' (Tunbridge Wells, Interviewee 11)

These extracts provide further evidence of limits or blocks to how strategic assessment is able to participate in strategic thinking and highlight the significance of the relationships between the various partners, be that assessment practitioners, plan makers or politicians. The emphasis is placed on influencing strategic thinking and decision-making happening in plan formulation rather than strategic assessment taking a more active role in strategic thinking itself.

These cases provide evidence that strategic assessment, both SA and SEA, include notions of strategic thinking as part of their purpose. However, strategic assessment appears frequently positioned as contributing to strategic thinking done elsewhere, i.e. the plan formulation process itself, rather than necessarily being engaged in strategic thinking directly. We find evidence of a reliance on influencing from a distance, rather than more direct involvement in strategic thinking. This presents the potential for strategic assessment to be viewed with a technical-rational perspective, functioning by identifying and documenting impacts to be reported back to plan makers. Strategic assessment excluded or distant from those aspects of plan formulation when strategic options are generated and debated, provides evidence that strategic thinking as part of strategic assessment purpose is framed within specific confines and may be absent in some applications. The ability of strategic assessment to meaningfully include, or participate in, strategic thinking and debate strategic issues, therefore, rests on the relationship between assessment and plan formation, and between the individuals involved in each.

\section{Concluding Discussion}

Literature establishes that multiple purposes for strategic assessment have accumulated over more than four decades of practice and conceptualisation (Fundingsland Tetlow \& Hanusch, 2012), and this research confirms the multifaceted nature of strategic assessment purpose. It provides evidence that this 
is reflected in practice and that different systems have constructed these purposes in different ways. Although the existence of multiple purposes is evident from literature, and Partidário (2000, p.655) is right to conclude SEA is best understood as a 'family of tools', we are able to add detail to that understanding, with evidence to suggest that multiple purposes are not independent, and are mediated and negotiated in practice.

Considering how these multiple purposes interact we find that regulatory requirements to conduct strategic assessment and a desire to demonstrate regulatory compliance are visible and influential elements of purpose in practice. In some cases, the dominance of regulatory compliance as a purpose can lead to strategic assessment becoming predominantly a tick box exercise - potentially stifling strategic thinking in favour of demonstrating regulatory compliance. However, we also find that regulatory compliance is not mutually exclusive to holding additional purposes and expectations. Indeed, evidence presented here demonstrates that within individual applications of strategic assessment there can exist the specific desire to achieve multiple benefits beyond compliance. This emphasises the importance of the individuals involved, and their knowledge and understanding of SEA/SA, to the manner in which strategic assessment and its purpose(s) are conceived in each application in practice.

When considering how strategic thinking is incorporated into practice, we argue that certain limitations and blocks exist, impeding how fully strategic assessment can participate in strategic thinking as part of plan formulation. As Noble (2000) argued, rather than being defined by the strategic tier, strategic assessment is fundamentally strategic and should be engaged in strategic thinking about the general direction and objectives of plan from the outset. Therefore, the ability of strategic assessment to participate in elements of plan formulation, such as objective setting and alternatives development, is argued to be crucial to strategic thinking. Moreover, we observe the desire to demonstrate regulatory compliance in strategic assessment practice possibly de-incentivises bespoke or tailored practice which embraces strategic thinking. This potential for the mixture of purposes to become dominated by one, potentially stifling other purposes for which strategic assessment might be set up to achieve, therefore requires practitioners to be cognisant of strategic assessment purposes and their (in)compatibilities.

While the cases analysed include strategic thinking to varying degrees, we find that often strategic assessment is framed as contributing to strategic thinking done elsewhere in plan formulation processes. This contribution, as opposed to more active participation, is described as influencing plan formulation and decision-making through information provision. Casting strategic assessment as information provider, potentially bringing a technical-rational perspective to plan formulation, has been described as concealing the political nature of decision-making (Cashmore et al., 2008) and rationalisation rather than rationality (Owens, 2005). Whilst there is variation between the cases, with some indicating a stronger ability to move beyond information provision towards ideas of actively influencing the plan formulation process, the use of vague language and caveats to describe the strength of influence masks how strategic assessment is able to participate in strategic thinking and decision-making. The evidence presented here shows limits or blocks to participation of strategic assessment in periods of strategic thinking, and that the ability of strategic assessment to genuinely participate in strategic thinking may be limited in practice. Exclusion from these elements or arenas of plan formulation also has implications for strategic assessment's ability to act as a mediator or means of communication as discussed by Partidário and Sheate (2013) and Morgan et al. (2012), further questioning how fully strategic assessment is able to be strategic.

As Illsley et al. (2014) noted, we show that when considering SA in England and SEA in Scotland there is evidence of a distinction in terms of a sustainability or environmental focus respectively. This 
distinction, particularly with regard to the environmental focus of SEA, can also be traced to the EU level. We are also been able to show that this distinction represented in legislation, filters through to practice and conditions how practitioners conceive of the role of SA or SEA. Perhaps as each system develops outside of the EU it will be possible make further comparisons with systems which see SEA as incorporating ideas of sustainability more fully (Gibson et al., 2010; White and Noble, 2013)?

While we have considered cases from England and Scotland, broader conclusions are possible from this analysis. In re-examining strategic assessment purpose in practice, we identify multiple features describing how multiple purposes interact, including; possible dominance, exclusion and limited influence. We argue that purpose is subject to multiple layers of influence, from international, to national, local and individual. We identify that international and national politics influence how whole systems of strategic assessment are set up and that perspectives at this scale are reflected in practice. Our analysis also identifies the importance of local relationships in the practice of strategic assessment - both the relationship between the processes of plan formulation and strategic assessment, as well as relationships between the individuals enacting each process. In local contexts specifically, the views plan makers and assessment practitioners hold about strategic assessment purpose have considerable bearing on subsequent practice, thus requiring specific consideration and reflection on these purposes at the outset of the application of strategic assessment. This is particularly important at a time of political flux for environmental regulations and assessment, for example, in the UK after the result of the 2016 UK referendum on leaving the EU, but also as we see environmental regulations questioned in Canada, the USA and elsewhere (Bond et al., 2016, Gibson, 2012 \& Percival, 2017). A clear understanding of the purpose(s) of strategic assessment is therefore important at both the practice level to avoid confusion and to be aware of compatibility issues, and more broadly to justify the continuation of strategic assessment, or to contribute to its reform.

\section{References}

Bina, O. (2007). A critical review of the dominant lines of argumentation on the need for strategic environmental assessment. Environmental Impact Assessment Review. 27, 585-606.

Bond, A. J., Fundingsland, M. \& Tromans, S. (2016). Environmental impact assessment and strategic environmental assessment in the UK after leaving the European Union, Impact Assessment and Project Appraisal. 34(3), 271-274.

Braun, V. \& Clarke, V. (2006). Using thematic analysis in psychology. Qualitative Research in Psychology. 3(2), 77-101.

Brown, A. L. \& Therivel, R. (2000). Principles to guide the development of strategic environmental assessment methodology. Impact Assessment and Project Appraisal. 18, 183-189.

Cashmore, M., Bond, A. J. \& Cobb, D. (2007). The contribution of environmental assessment to sustainable development: Toward a richer empirical understanding. Environmental Management. 40, 516-530.

Cashmore, M., Bond, A. J. \& Cobb, D. (2008). The role and functioning of environmental assessment: Theoretical reflections upon an empirical investigation of causation. Journal of Environmental Management. 88, 1233-1248.

Cashmore, M., Gwilliam, R., Morgan, R., Cobb, D. \& Bond, A. J. (2004). The interminable issue of effectiveness: substantive purposes, outcomes and research challenges in the advancement of environmental impact assessment theory. Impact Assessment and Project Appraisal. 22, 295 310.

Department for Communities and Local Government (2008). Planning Policy Statement 12: creating strong safe and prosperous communities through Local Spatial Planning. London: The Stationery Office. 
Department for Communities and Local Government (2014). National Planning Practice Guidance: Strategic environmental assessment and sustainability appraisal. London: Department for Communities and Local Government.

Devuyst, D. (2001). Linking Impact Assessment with Sustainable Development and the Introduction of Strategic Environmental Assessment. In: Devuyst, D., Lannoy, W. D. \& Hens, L. (eds.) How green is the city?: sustainability assessment and the management of urban environments. New York: Columbia University Press.

Elling, B. (2009). Rationality and effectiveness: does EIA/SEA treat them as synonyms? Impact Assessment \& Project Appraisal. 27, 121-131.

European Commission Environment Directorate-General (2001). Implementation of Directive 2001/42 on the Assessment of the Effects of Certain Plans and Programmes on the Environment. Brussels: European Commission Environment Directorate-General.

European Parliament and the Council of the European Union (2001). Directive 2001/42/EC of the European Parliament and of the Council of 27 June 2001 on the assessment of the effects of certain plans and programmes on the environment. Brussels: Official Journal of the European Communities.

Falkirk Council (2007). Falkirk Council local plan finalised draft (deposit version) strategic environmental assessment. Falkirk: Falkirk Council.

Falkirk Council (2011). Falkirk Council Local Plan: Post Adoption Strategic Environmental Assessment Statement. Falkirk: Falkirk Council.

Fischer, T. B. (2003). Strategic environmental assessment in post-modern times. Environmental Impact Assessment Review. 23, 155-170.

Fischer, T. B. (2007). Theory and Practice of Strategic Environmental Assessment: towards a more systematic approach. London: Earthscan.

Fundingsland Tetlow, M. \& Hanusch, M. (2012). Strategic environmental assessment: the state of the art. Impact Assessment and Project Appraisal. 30, 15-24.

Gasparatos, A., El-Haram, M. \& Horner, M. (2009). The argument against a reductionist approach for measuring sustainable development performance and the need for methodological pluralism. Accounting Forum. 33, 245-256.

Gibson, R. B. (2006). Beyond the Pillars: Sustainability Assessment as a Framework for Effective Intergration of Social, Economic and Ecological Considerations in Significant DecisionMaking. Journal of Environmental Assessment Policy \& Management. 8, 259-280.

Gibcon, R. B., Benevides, H., Doelle, M. \& Kirchhoff, D. (2010). Strengthening Strategic Environmental Assessment in Canada: An Evaluation of Three Basic Options. Journal of Environmental Law and Practice, 20(3), 175-211.

Gibson, R. B. (2012). In full retreat: the Canadian government's new environmental assessment law undoes decades of progress, Impact Assessment and Project Appraisal. 30(3), 179-188.

Glasson, J., Therivel, R. \& Chadwick, A. (2005). Introduction to environmental impact assessment. London: Routledge.

Hacking, T. \& Guthrie, P. (2008). A framework for clarifying the meaning of Triple Bottom-Line, Integrated, and Sustainability Assessment. Environmental Impact Assessment Review. 28, 7389.

Illsley, B., Jackson, T. \& Deasley, N. (2014). Spheres of public conversation: Experiences in strategic environmental assessment. Environmental Impact Assessment Review, 44, 1-10.

Jackson, T. \& Illsley, B. (2007). An analysis of the theoretical rationale for using strategic environmental assessment to deliver environmental justice in the light of the Scottish Environmental Assessment Act. Environmental Impact Assessment Review. 27, 607-623.

Jones, C. E., Barker, M., Carter, J., Jay, S., Short, M. \& Wood, C. (2005). Introduction. In: Jones, C. E., Barker, M., Carter, J., Jay, S., Short, M. \& Wood, C. (eds.) Strategic environmental assessment and land use planning: an international evaluation. London: Earthscan.

Kørnøv, L. \& Thissen, W. (2000). Rationality in decision- and policy-making: implications for strategic environmental assessment. Impact Assessment and Project Appraisal, 18, 191-200.

Lee, N. \& Walsh, F. (1992). Strategic environmental assessment: an overview. Project Appraisal. 7 , 126-136. 
Levi-Faur, D. (2006). A Question of Size? A Heuristics for Stepwise Comparative Research Design. In: Rihoux, B. \& Grimm, H. (eds.) Innovative Comparative Methods for Policy Analysis: Beyond the Quantitative-Qualitative Divide. New York: Springer.

Morgan, R. K., Hart, A., Freeman, C., Coutts, B., Colwill, D. \& Hughes, A. (2012). Practitioners, professional cultures, and perceptions of impact assessment. Environmental Impact Assessment Review. 32(1), 11-24.

Morrison-Saunders, A. \& Fischer, T. B. (2006). What is wrong with EIA and SEA anyway? A sceptic's perspective on sustainability assessment. Journal of Environmental Assessment Policy and Management. 8, 19-39.

Nitz, T. \& Brown, A. (2001). SEA Must Learn How Policy Making Works. Journal of Environmental Assessment Policy \& Management. 3, 329-342.

Noble, B. F. (2000). Strategic environmental assessment: what is it? \& what makes it strategic? Journal of Environmental Assessment Policy and Management. 2, 203-224.

Noble, B. F. \& Nwanekezie, K. (2016). Conceptualizing strategic environmental assessment: Principles, approaches and research directions. Environmental Impact Assessment Review, 62, 165-173.

Office of the Deputy Prime Minister (2004). The Environmental Assessment of Plans and Programmes Regulations 2004. London: The Stationery Office.

Office of the Deputy Prime Minister (2005). A practical guide to the strategic environmental assessment directive: practical guidance on applying European directive 2001/42/EC "on the assessment of the effects of certain plans and programmes on the environment". London: Office of the Deputy Prime Minister.

Owens, S. (2005). Making a difference? Some perspectives on environmental research and policy. Transactions of the Institute of British Geographers. 30, 287-292.

Partidário, M. R. (2000). Elements of an SEA framework - improving the added-value of SEA. Environmental Impact Assessment Review. 20, 647-663.

Partidário, M. R. \& Sheate, W. R. (2013). Knowledge brokerage - potential for increased capacities and shared power in impact assessment. Environmental Impact Assessment Review. 39, 26-36.

Percival, R. V. (2017) Environmental Law in the Trump Administration. 4 Emory Corporate Governance and Accountability Review. 2017-5, 225-235.

Perth \& Kinross Council (2009). Environmental Report. Perth: TAYplan Strategic Development Planning Authority.

Richardson, T. (1996). Foucauldian discourse: Power and truth in Urban and regional policy making. European Planning Studies. 4, 279 - 292.

Robson, C. (2011). Real world research: a resource for users of social research methods in applied settings (Third Edition). Oxford: Wiley-Blackwell.

Saldaña, J. (2009). The Coding Manual for Qualitative Researchers. London: Sage.

Scottish Executive Environment Group (2003). Strategic Environmental Assessment: A Consultation on Proposed Legislative Measures to Introduce Strategic Environmental Assessment in Scotland. Edinburgh: Scottish Executive.

Scottish Government (2005). Environmental Assessment (Scotland) Act. London: The Stationery Office.

Scottish Government (2006). The Planning etc. (Scotland) Act 2006. London: The Stationery Office.

Scottish Government (2011). About Strategic Environmental Assessment in Scotland [Online]. Edinburgh: Scottish Government. Available:

http://www.scotland.gov.uk/Topics/Environment/environmental-assessment/sea/about [Accessed 19/06/2015].

Scottish Government (2013). Strategic Environmental Assessment Guidance. Edinburgh: Scottish Government.

Scottish Labour Party \& Scottish Liberal Democrats (2003). A Partnership for a Better Scotland: Partnership Agreement. Edinburgh: Scottish Government.

Sheate, W. R. (2011). SEA and environmental planning and management tools. In: Sadler, B., Aschemann, R., Dusik, J., Fischer, T. B., Partidário, M. R. \& Verheem, R. (eds.) Handbook of strategic environmental assessment. London: Earthscan. 
Sheate, W. R. \& Partidário, M. R. (2010). Strategic approaches and assessment techniques - Potential for knowledge brokerage towards sustainability. Environmental Impact Assessment Review. 30, 278-288.

Smith, S. \& Sheate, W. R. (2001). Sustainability appraisal of English regional plans: incorporating the requirements of the EU Strategic Environmental Assessment Directive. Impact Assessment and Project Appraisal. 19, 263-276.

Tajima, R. \& Fischer, T. B. (2013). Should different impact assessment instruments be integrated? Evidence from English spatial planning. Environmental Impact Assessment Review. 41, 2937.

Tayplan Strategic Development Planning Authority (2009). SEA Scoping Report. Dundee: TAYplan Strategic Development Planning Authority.

Tesserae Environmental Consultants (2007). Sustainability Appraisal and Strategic Environmental Assessment of the Black Country Joint Core Strategy: Incorporating Equality Impact Assessment and Health Impact Assessment. Brighton: Tesserae Environmental Consultants.

Tesserae Environmental Consultants (2008). Sustainability Appriasal of the Black Country Joint Core Strategy preferred Options Report. Brighton: Tesserae Environmental Consultants.

Therivel, R. (2004). Strategic environmental assessment in action. London: Earthscan.

Therivel, R. \& Partidário, M. R. (1996). Introduction. In: Therivel, R. \& Partidário, M. R. (eds.) The practice of strategic environmental assessment. London: Earthscan.

UK Government (2004). Planning and Compulsory Purchase Act 2004. London: The Stationery Office.

Van Doren, D., Driessen, P. P. J., Schijf, B. \& Runhaar, H. A. C. (2013). Evaluating the substantive effectiveness of SEA: Towards a better understanding. Environmental Impact Assessment Review. 38, 120-130.

Verma, N. (1996). Pragmatic Rationality and Planning Theory. Journal of Planning Education and Research. 16, 5-14.

Vicente, G. \& Partidário, M. R. (2006). SEA - Enhancing communication for better environmental decisions. Environmental Impact Assessment Review. 26, 696-706.

Waterman Environmental (2005). Sustainability Appraisal Scoping Report: Local Development Framework, Tunbridge Wells Borough. London: Tunbridge Wells Borough Council.

Waterman Environmental (2007). Initial Sustainability Appraisal Tunbridge Wells Borough Local Development Framework - Issues and Options Report. London: Tunbridge Wells Borough Council.

Weston, J. (2004). EIA in a risk society. Journal of Environmental Planning and Management. 47, 313-325.

White, L. \& Noble, B. F. (2013). Strategic environmental assessment for sustainability: A review of a decade of academic research. Environmental Impact Assessment Review, 42, 60-66.

Wood, C. (2003). Environmental impact assessment: A Comparative Review. Harlow: Prentice Hall.

Wood, C. M. \& Djeddour, M. (1989). Environmental assessment of policies, plans and programmes. Interim report to the Commission of European Communities. Manchester: EIA Centre, University of Manchester.

Yin, R. (2009). Case Study Research: Design and Methods (Fourth Edition. Vol. 5). London: Sage. 